\title{
CRISE DE HEGEMONIA E EMERGÊNCIA DE NOVOS ATORES NA BOLÍVIA: 0 GOVERNO DE EVO MORALES
}

Luis Fernando Ayerbe

\section{O nacionalismo revolucionário}

A insurreição popular que coloca no poder em 1952 o Movimiento Nacionalista Revolucionario (MNR) marca o momento culminante de um processo de crise econômica, política e social que se iniciou com a queda dos preços internacionais do estanho a partir de 1929 e a derrota da Bolívia para o Paraguai na Guerra do Chaco (1932-1935) ${ }^{1}$.

Nas primeiras décadas do século XX, a Bolívia consolida sua posição como segundo produtor mundial de estanho², atrás da Malásia. Em 1930, esse minério é responsável por $74 \%$ das exportações bolivianas, sendo que a prata, chumbo, zinco, cobre, bismuto, tungstênio e antimônio

\footnotetext{
${ }^{1} \mathrm{O}$ motivo da guerra foi a pretensão boliviana de ter acesso ao rio Paraguai através do Chaco. Posteriormente, acusou-se a Standard Oil de ter influenciado na decisão de declarar a guerra, por causa da disputa com a Royal Dutch Shell pelas reservas petrolíferas no Paraguai e sua intenção de obter uma saída pelo Atlântico, através da Bacia do Prata, para sua produção na Bolívia.

${ }^{2} \mathrm{O}$ controle de $74 \%$ dessa produção de estanho se concentrava em três grupos privados. O mais poderoso deles, dirigido por Simon Patiño, detinha quase 59\% em 1929, em segundo lugar vinha o de Mauricio Hotchschild, com $10 \%$ e em terceiro o de Felix Aramayo, com 5\%.
} 
representavam 20\%. Essa consolidação do modelo mineiro-exportador coincide, no plano político, com uma fase de estabilidade institucional em que governos conservadores, liberais e republicanos se sucedem no poder.

A alta constante dos preços internacionais do estanho não se traduzia, para o conjunto da economia boliviana, num grande impulso dinamizador. Participando com $40 \%$ do PIB, a mineração ocupava $4 \%$ da PEA. A agricultura, de baixa produtividade e com uma estrutura da propriedade altamente concentrada, ocupava $64 \%$ da PEA sem, contudo, conseguir abastecer o mercado interno, devendo-se recorrer à importação de vários produtos.

A oligarquia mineiro-exportadora, que exercia o controle político do país, praticamente não pagava impostos, o que mantinha o Estado em crise fiscal permanente, recorrendo a empréstimos externos para equilibrar suas contas. Por causa dessa limitada capacidade de irradiação dos bene180 fícios da prosperidade para o conjunto do país, o setor era conhecido popularmente como "rosca", porque girava em torno si mesmo.

A derrota na Guerra do Chaco, com a consequente humilhação, perda de territórios e agudização da crise econômica, provoca o desprestígio do Exército, responsabilizado, junto com a "rosca", pelo fracasso. Surgem grupos militares nacionalistas, que passam a conspirar politicamente contra os setores dominantes. Aumenta a organização sindical dos trabalhadores, que, em 1937, criam a Confederación Sindical de Trabajadores de Bolivia (CSTB). Em 1934, é fundado o Partido Obrero Revolucionario (POR), de linha trotskista, em 1940, o Partido de la Izquierda Revolucionaria (PIR), ligado à Terceira Internacional, e, em 1941, o MNR, com bases de apoio nos setores nacionalistas do Exército e nas classes médias.

Por duas vezes na década de 1930, com os golpes militares que levam à Presidência David Toro (1936) e German 
Busch (1937), os grupos nacionalistas do Exército tentam mudar os rumos do país, colocando a oligarquia mineira como alvo prioritário das reformas. No entanto, com o início da Segunda Guerra, o estanho boliviano adquire importância fundamental para os aliados, na medida em que o Japão controla a outra fonte fornecedora na Ásia. O que poderia ser uma excelente oportunidade de melhorar o saldo exportador, com preços mais competitivos, se frustra por causa das pressões dos Estados Unidos para que, em nome da "solidariedade continental" com os aliados, a Bolívia assine um contrato por cinco anos, comprometendo-se a vender a libra de estanho a um preço fixo de 0,42 dólares para EUA e Inglaterra. Isso significou, entre 1941 e 1945, uma “ajuda” de 670,315 milhões de dólares".

Em 1940, um golpe militar destitui o governo Busch e restaura o poder dos setores dominantes tradicionais, colocando na Presidência o general Enrique Peñaranda. A crise econômica e a instabilidade política marcam o período entre 1940 e 1951. Uma sucessão de golpes militares coloca alternadamente no poder nacionalistas como Gualberto Villarroel (1943), apoiado pelo MNR, e conservadores como Enrique Herzog, eleito em 1947 após a destituição e linchamento de Villarroel.

Esse grau de antagonismo e radicalidade dos setores dominantes com Villarroel deveu-se em grande medida à sua política indigenista, na contramão do tratamento discriminatório que pautou as elites que assumem o poder na Bolívia após a sua independência da Espanha. Em 1944, deixa sem efeito a legislação que proibia a livre circulação dos índios pelas ruas e praças das cidades e em 1945 apoia a realização do Primeiro Congresso Indígena, assumindo

\footnotetext{
${ }^{3}$ Ver em Plá (1986, p. 123), dados do Conselho Internacional do Estanho no Statistical Yearbook que comparam os preços controlados com os preços no livre mercado.
} 
parte importante das reivindicações apresentadas pelas suas lideranças, como a proibição da servidão pessoal e do trabalho gratuito para os proprietários de terra, sancionada no mesmo ano pelo Decreto Supremo n. 319.

Apesar das tentativas reformistas ensaiadas pelos nacionalistas, os fundamentos da estrutura socioeconômica da Bolívia permanecem inalterados. A repressão que se sucede à derrocada de Villarroel busca restaurar a paz social e política das primeiras décadas do século. Quando Mamerto Urriolagoitia, sucessor de Herzog, convoca eleições gerais para 1951, o objetivo de governar com legitimidade é contrariado pelo resultado das urnas, que dão a vitória à coligação entre o MNR, o Partido Comunista (fundado em 1950) e o POR, encabeçada por Victor Paz Estenssoro. O desconhecimento do resultado das urnas e a entrega do poder a uma junta militar desencadeiam uma insurreição popular que, em três dias, derrota o Exército e entrega o poder ao 182 vencedor das eleições.

As principais medidas do novo governo dão uma clara sinalização de ruptura com o passado:

1. A nacionalização das minas, ao mesmo tempo que expropria a maior parte do capital estrangeiro investido no país, elimina o poder econômico da oligarquia mineira. Cria-se a Corporación Minera de Bolivia (Comibol) que concentra no Estado a gestão dos recursos minerais.

2. A reforma agrária busca acabar com o latifúndio e com a oligarquia rural. A democratização da propriedade da terra tem como objetivo econômico aumentar a produtividade para atingir o autoabastecimento e melhorar o nível do consumo interno, estimulando a expansão da demanda de bens de consumo manufaturados.

3. O sufrágio universal abre espaço para a participação político-institucional dos analfabetos, que compõem $70 \%$ da população. 


\section{Tabela 1}

PIB Estimado da Bolívia (1952-64).

A Preços Constantes de 1958 em Milhões de Dólares

\begin{tabular}{|c|c|c|c|c|c|c|c|c|c|c|c|}
\hline Setores & 1952 & 1954 & 1956 & 1957 & 1958 & 1959 & 1960 & 1961 & 1962 & 1963 & 1964 \\
\hline Agricultura & 131,1 & 101,7 & 104,2 & 110,7 & 121,5 & 128,6 & 121,9 & 131,9 & 136,4 & 141,2 & 149,6 \\
\hline Mineração & 58,3 & 48,3 & 46,1 & 47,4 & 32,7 & 31,2 & 33,8 & 37,7 & 35,4 & 40,2 & 43,0 \\
\hline Petróleo & 2,1 & 6,9 & 13,1 & 14,7 & 14,2 & 13,3 & 14,6 & 13,2 & 14,2 & 14,7 & 14,8 \\
\hline Indústria & 49,0 & 54,9 & 51,4 & 36,0 & 39,5 & 41,5 & 44,6 & 45,3 & 48,2 & 49,5 & 54,6 \\
\hline Construção & 3,6 & 2,5 & 2,6 & 3,1 & 4,1 & 4,3 & 5,4 & 1,9 & 2,2 & 3,4 & 3,9 \\
\hline Comércio/Bancos & 48,5 & 42,5 & 45,8 & 47,0 & 45,3 & 46,4 & 47,3 & 43,0 & 45,6 & 51,8 & 54,1 \\
\hline Transporte & 23,9 & 26,4 & 29,7 & 27,1 & 30,0 & 30,8 & 31,4 & 33,4 & 37,0 & 39,1 & 41,4 \\
\hline Governo (*) & 55,0 & 28,6 & 26,0 & 20,7 & 27,1, & 28,0 & 31,9 & 32,5 & 34,5 & 37,0 & 39,7 \\
\hline Outros serviços & 34,3 & 34,4 & 35,9 & 36,2 & 36,8 & 37,7 & 38,6 & 43,0 & 44,3 & 45,6 & 47,5 \\
\hline PIB & 387,8 & 346,2 & 354,8 & 342,9 & 351,2 & 361,8 & 369,5 & 381,9 & 397,8 & 422,5 & 448,6 \\
\hline PIB per capita & 122,0 & 104,0 & 102,0 & 96,0 & 96,2 & 96,8 & 96,6 & 97,4 & 99,0 & 102,5 & 106,2 \\
(em dólares) & & & & & & & & & & & \\
\hline
\end{tabular}

(*) Excluiu-se os organismos descentralizados.

Fonte: Secretaria Nacional de Planejamento apud Plá (1986, p. 91).

4. O estabelecimento da obrigatoriedade da educação universal e gratuita, com forte impacto na escolarização, terá desdobramentos na formação de lideranças intelectuais oriundas dos setores populares, especialmente indígenas.

5. A liquidação do Exército outorga amplos poderes ao novo governo para transitar pelo caminho das reformas sem ter que transigir frente a um poder armado fora do seu controle.

Para Maria Eugenia Choque e Carlos Mamani Condori, intelectuais de origem aimará, o processo conduzido pelo MNR em 1952 estabelece um divisor de águas "entre o período colonial de exclusão dos povos indígenas da ideia de Estado-nação e outro período de inclusão mediante a assimilação" (2003, p. 148). No entanto, apesar dessa ruptura efetiva com o passado, a aposta dos participantes da revo- 
lução em favor do início de uma fase de superação do subdesenvolvimento não se configura como realidade palpável nos indicadores econômicos. Como mostra a tabela 1, com exceção do petróleo, há uma regressão generalizada em todos os setores.

Na mineração, a política adotada de utilizar parte da renda para financiar outras áreas da economia, somada ao agravamento de problemas estruturais associados com a queda de produtividade, falta de manutenção e reposição de equipamentos e as indenizações pagas pela expropriação (22 milhões de dólares), levam a uma descapitalização do setor. Entre 1952 e 1960, as exportações diminuem de 136 para 55 milhões de dólares, sendo que $84 \%$ delas são destinadas aos Estados Unidos e à Inglaterra. Ao mesmo tempo, o transporte e a fundição continuam nas mãos de empresas estrangeiras, o que mantém o país dependente do exterior.

184 As mudanças no campo estiveram aquém das expectativas. A Lei de Reforma Agrária não afetou o conjunto da grande propriedade, deixando de fora da definição de latifúndio as terras "trabalhadas com máquinas e métodos modernos, as que estivessem pessoalmente dirigidas por seus proprietários e as que contassem com investimentos de capital suplementar" (Hernandez e Salcito, 2007, p. 147). Com base nesses critérios, as expropriações se concentraram na parte andina do país, em que predominavam os latifúndios tradicionais, assim, pouparam-se as terras situadas nas regiões de planície e se favoreceu a expansão da grande propriedade no oriente, especialmente a província de Santa Cruz de la Sierra.

Na região do altiplano, a distribuição de terras foi bastante rápida, atingindo 4,4 milhões de hectares até 1963. No entanto, o processo de transição entre antigos e novos proprietários, com os problemas políticos decorrentes, afeta os níveis de produção. Paralelamente, 
o excessivo parcelamento das terras, não acompanhado por medidas eficazes para promover a cooperativização, impedia a tecnificação e mantinha intactos os arcaicos procedimentos de cultivo. Muitas parcelas apenas abasteciam o consumo familiar - incrementado pelas melhores condições de vida - e não produziam quase excedentes comerciais. A falta de créditos e o escasso assessoramento técnico afogavam as intenções progressistas, e a manutenção de primitivos e antieconômicos procedimentos de comercialização diminuía a renda dos camponeses (Del Campo, 1986, p. 50).

A produção agrícola não aumentou ao ponto de satisfazer o mercado interno, mantendo-se a necessidade de importação; a agricultura continuou num estágio de subsistência, permanecendo baixa a demanda por produtos industrializados; a produção industrial estacionou num patamar de $9 \%$ do PIB, ocupando $4 \%$ da PEA e abastecendo $40 \%$ do consumo de manufaturados (Del Campo, 1986, p. 50).

A deterioração da situação econômica convive com um processo inflacionário e de desvalorização cambial, ao que se soma uma crescente instabilidade política originária do alto grau de mobilização da classe operária mineira e dos setores médios urbanos. Os camponeses beneficiados pela repartição de terras tendem a assumir posturas políticas moderadas.

Para o MNR e suas figuras políticas principais, Victor Paz Estenssoro e Hernán Siles Suazo, as mudanças estruturais provocadas pelas reformas tinham atingindo um limite que não deveria ser transposto. Para sair do atraso econômico e social, era preciso controlar a "desordem" e definir um caminho de desenvolvimento. Sob a pressão das circunstâncias, temendo mais os desdobramentos da crescente ativação popular do que a negociação com os Estados Unidos, optam pelo segundo caminho. 
A partir de 1953, o Exército é reestruturado e a maioria dos novos egressos do Colégio Militar passa a receber treinamento nos programas do Pentágono no Canal de Panamá. Em 1964, mais da metade da alta oficialidade tinha passado pelas escolas dos Estados Unidos, a maior porcentagem em comparação aos outros países latino-americanos, o que terá reflexos políticos de longo alcance (Ayerbe, 2002).

Em 1955, o novo Código de Petróleo outorga concessões de mais de 11 milhões de hectares a empresas estrangeiras, beneficiando especialmente a Bolivian Gulf Company, de origem estadunidense. Em 1956, o novo presidente eleito, Siles Suazo, implementa um plano de estabilização negociado com o $\mathrm{FMI}^{4}$, que entre as principais medidas,

estabelecia drásticas reduções do orçamento - que obrigaram a abandonar a maior parte das obras de desenvolvimento - e restringia ao máximo os créditos.

O tipo único e livre de câmbio implicava a eliminação dos subsídios de que tinham se beneficiado os produtos importados de primeira necessidade. Abandonou-se o controle dos preços e os salários foram congelados (Del Campo, 1986, p. 50).

O plano de estabilização implicou numa deterioração ainda maior dos indicadores sociais e apenas controlou a inflação. O sentido restaurador de privilégios presente na postura com relação ao capital estrangeiro elevou a agita-

\footnotetext{
${ }^{4}$ A Bolívia foi o primeiro país da América Latina a fazer um acordo com o FMI. Entre 1956 e 1960, a lista de créditos concedidos pelo FMI foi da seguinte ordem: "Argentina, de 1958 a 1960, 275 milhões de dólares; Bolívia, de 1956 a 1957, 27 milhões de dólares; Chile, de 1956 a 1959, 63,6 milhões; Colômbia, de 1956 a 1960, 157,25 milhões; México, 50 milhões em 1954 e 90 em 1959; Nicarágua, de 1956 a 1960, 26,25 milhões; Paraguai, de 1957 a 1960, 13,25 milhões; Peru, de 1955 a 1960, 91 milhões; Rep. Dominicana, 1959, 11,25 milhões; Uruguai, 1960, 30 milhões e Venezuela, 1960, 100 milhões. Apenas escaparam Brasil, Cuba e Panamá; mas dezessete repúblicas austrais se submeteram. Foram concedidos 48 empréstimos e assinados dez convênios stand by até fins de 1960" (Trias, 1977, pp. 272-273).
} 
ção política e os partidos de esquerda romperam a aliança com o MNR. Por outro lado, os Estados Unidos reagem favoravelmente à nova orientação. Relatório de inteligência do Departamento de Estado em 31 de janeiro de 1958 ressalta as virtudes estabilizadoras do governo de Siles Suazo:

O regime do Movimiento Nacionalista Revolucionario [...] continua a representar a única organização capaz de manter um equilíbrio entre as principais forças sociais e políticas na Bolívia. Sua habilidade de preservar um governo estável e uma orientação pró-EUA na Bolívia durante os próximos anos será condicionada em grande parte pelo nível de assistência externa que ela possa receber. Nem a oposição direitista nem os partidos comunistas ameaçarão a estabilidade contínua, exceto em caso de séria deterioração econômica. [...] O curso da prudência seguido pelo MNR durante seu primeiro período no poder conferiu-lhe amplo apoio, e nas eleições de 1956, seu líder, Hernán Siles Zuazo, recebeu um evidente mandato popular (OSS apud Kesaris, 1979).

Siles Suazo chegará ao final de seu mandato, sendo sucedido por Victor Paz Estenssoro. Na sua segunda presidência, o principal apoio com que conta se encontra no Exército, representado na Vice-Presidência por René Barrientos, militar treinado nos Estados Unidos, só que esse apoio está condicionado à capacidade do governo eleito de manter a governabilidade. Em pouco tempo, os receios explicitados no documento do Departamento de Estado acima citado se concretizam. O vice-presidente encabeça um golpe militar, com pouquíssima resistência, iniciando um ciclo de instabilidade institucional em que as forças armadas assumem o papel principal no controle do poder político.

Os governos militares que presidem o país entre 1964 e 1971, mantém no essencial a trajetória iniciada com a revo- 
lução de 1952. René Barrientos estabelecerá acordos com sindicatos camponeses com o objetivo de consolidar apoios num cenário de conflito com os setores trabalhadores, atingidos por medidas de corte salarial e por políticas repressivas cujos alvos principais são a Central Obrera Boliviana (COB), fundada em 1952, e a militância de esquerda. Como parte dessa estratégia, acorda o Pacto Militar-Camponês, envolvendo a ampliação da distribuição de terras, que atinge 7,6 milhões de hectares até 1967 (Hernandez e Salcito, 2007). A morte inesperada e misteriosa de Barrientos num acidente aéreo em abril 1969 desencadeia uma crise política, com a deposição do seu vice-presidente Siles Salinas pelo general Alfredo Ovando Candia, destituído um ano depois, abrindo espaço para a ascensão do general Juan José Torres, que busca retomar as reformas de 1952, especialmente na distribuição da terra e na nacionalização do setor minerador.

188 Torres busca apoio nos setores populares reunidos em torno da Assembleia Popular, órgão criado no primeiro de maio de 1971, que contava com a participação de organizações de esquerda e da COB. No entanto, a experiência tem curta duração, em 21 de agosto setores das forças armadas comandados pelo general Hugo Banzer, com apoio do governo brasileiro e da embaixada dos Estados Unidos, derrubam o presidente Torres e instauram um novo regime militar.

A ditadura de Banzer (1971-78) abre um ciclo autoritário com implicações que vão muito além da abertura ao capital estrangeiro, o alinhamento com os Estados Unidos e a repressão à militância partidária e sindical que marcam o perfil conservador que tende a se afirmar na América Latina. A Bolívia se insere de forma crescente e profunda no circuito mundial do tráfico de drogas com base na produção de cocaína.

A partir de 1975, a crise econômica leva setores aliados do regime banzerista com investimentos na agricultura 
a diversificarem as culturas de exportação, estimulando a plantação de coca. De acordo com Delpirou e Labrousse,

Enquanto em 1976 a produção de folhas era avaliada em torno de 10 mil toneladas, estima-se que ela tenha atingido 25 mil toneladas em 1977. Como as necessidades para o uso tradicional não ultrapassam 4 mil toneladas, 21 mil toneladas de folha serviram para a elaboração de 87 toneladas de pasta de base (1988, pp. 150-151).

O país torna-se um dos alvos principais da nova agenda estadunidense de combate ao tráfico de drogas iniciada pelo governo de Ronald Reagan, que vincula o problema com a segurança nacional, extrapolando o âmbito interno e policial da repressão, para transformar-se em tema de política externa. Para reduzir os custos políticos internos de uma repressão mais efetiva ao consumo, a ênfase será dada ao lado da oferta do produto, ao atingir de maneira mais violenta as fontes produtoras. No âmbito regional, a assinatura de convênios bilaterais permitirá a participação de assessores militares dos Estados Unidos e da Drug Enforcement Administration (DEA), criada na administração de Richard Nixon, no treinamento das forças de segurança e na implementação de programas de erradicação das plantações e substituição por outros cultivos. Buscando uma ação internacional mais abrangente, o Congresso estadunidense aprova, em 1986, uma lei que solicita que o seu presidente "certifique" anualmente os países que colaboram com o combate ao tráfico de drogas que tem como destino os Estados Unidos.

$\mathrm{O}$ envolvimento das forças armadas bolivianas com o narcotráfico atingiu níveis alarmantes a partir do golpe militar encabeçado pelo general Luis García Mesa em 1980, que coloca nos postos-chaves do poder, incluindo a Presidência, pessoas com reconhecida participação no tráfico de drogas. 
A intervenção de Mesa busca restaurar o poder militar, sob forte inspiração das ditaduras então vigentes na Argentina, Chile e Uruguai, após a falha tentativa de Banzer de institucionalizar a continuidade do seu regime através de eleições. Seu candidato pela Unión Nacionalista del Pueblo (UNP), Juan Pereda, foi derrotado em 1978 pela Unidad Democrática y Popular (UDP) liderada por Siles Suazo. No entanto, as eleições são anuladas e o país passa a vivenciar quatro anos de forte instabilidade, com a sucessão de nove presidentes. Em 1981, ao enfrentar forte isolamento político com denúncias sobre violação dos direitos humanos e vínculos com a criminalidade, renuncia García Mesa, sendo posteriormente julgado e encarcerado. Em 1983, o Congresso nomeia Hernán Siles Suazo para a Presidência do país, dando início a um processo de redemocratização.

\section{Liberalização política e econômica}

190 A transição política convive com uma situação de crise econômica estrutural, com o esgotamento do modelo mineiro-exportador (cujos níveis de atividade representam um terço com relação a 1971), a retração da atividade agropecuária, o alto endividamento externo e a expansão da economia da coca em níveis que colocam em xeque a capacidade de ação do Estado.

Em termos da pauta exportadora, o gás natural substitui o estanho como principal produto. A Argentina torna-se o principal mercado ao absorver $55 \%$ das exportações em 1985, e Brasil equipara-se aos Estados Unidos ao representar $22 \%$ das compras externas da Bolívia. A reorientação do comércio exterior em direção aos países da região acontece paralelamente à redução do volume das exportações, causado pela queda dos preços internacionais da maioria dos produtos minerais, que acompanham outros indicadores negativos do período 1981-1985, como a redução do PIB em 19,2\%, do PIB per capita em 29,4\% (Chaves Alvarez, 1988) e 
elevação da inflação de 296,5\% em 1982 a 2.177,2 em 1984 e 8.170,5 em 1985 (Cepal, 1990). Na economia informal, "O produto interno bruto subterrâneo, associado à produção de cocaína entre 1981-1985, registrou crescimento fantástico, alcançando aumento de $493 \%$ para o período 1980-1985, sendo que a taxa anual média de crescimento foi da ordem de 34,5\%" (Chaves Alvarez, 1988, p. 13).

Durante a presidência de Siles Suazo, os problemas decorrentes da forte presença do tráfico de entorpecentes na vida do país, somados às dificuldades no campo econômico, desencadeiam uma crise de governabilidade. Dois fatos dão uma medida da situação inédita vivida pelo presidente: em 30 de junho de 1984, durante dez horas, um grupo vinculado ao tráfico de drogas e formado por membros do Exército e da polícia o sequestra; no final de outubro, inicia uma greve de fome em protesto contra dúvidas levantadas pelo Congresso com relação a sua conduta na luta contra o narcotráfico.

A partir das eleições de 1985, em que Victor Paz Estenssoro volta a ocupar a Presidência do país, estabelece-se uma aliança entre os principais partidos conservadores, com base na Acción Democrática Nacionalista (ADN) de Hugo Banzer e o Movimiento Nacionalista Revolucionario do presidente, em favor da aplicação de um programa de reformas econômicas inspirado na experiência chilena de Augusto Pinochet.

Embora a eleição de Paz Estenssoro não alimentasse grandes expectativas em favor de uma gestão voltada para os setores populares, ainda existia a lembrança do nacionalismo que inspirou a revolução de 1952. Não se previa uma guinada tão drástica como a que se materializa na Nova Política Econômica lançada logo após a posse, em setembro de 1985. Sob o comando do seu ministro, e futuro presidente também pelo MNR, Gonzalo Sánchez de Lozada, determina-se a liberalização dos preços, da taxa de juros, 
do câmbio e dos salários; a abertura comercial e financeira externa; a privatização de empresas públicas; o fim do monopólio estatal no transporte aéreo e terrestre e o fim da estabilidade no emprego.

A reação dos trabalhadores será a deflagração de uma greve geral, inicialmente por 48 horas e que se estende por tempo indeterminado a partir da radicalização do governo, que decreta o estado de sítio até conseguir o esvaziamento do movimento.

Acerca do controle da inflação, há uma melhoria: $66 \%$ em 1986, 10,7\% em 1987 e taxas estáveis em torno de 20\% até o final da década. O PIB sofre uma queda de 2,5\% em 1986, mas se recupera lentamente nos anos seguintes, no entanto, o PIB por habitante decai 4,9\% em 1986, mantendo-se estável nos anos seguintes (Cepal, 1990).

Com relação ao narcotráfico, o programa econômico, através da liberalização do câmbio, facilitou o ingresso no 192 sistema financeiro dos dólares obtidos com a coca. Ao mesmo tempo, com a decretação de uma anistia tributária que estabelece um imposto para regularizar o patrimônio das pessoas físicas e jurídicas junto à receita federal, permite-se a legalização de fortunas com origem incerta. Para a economia nacional, isto significou um aumento das reservas em divisas e a repatriação de capitais, contribuindo para a estabilização do câmbio e o controle da inflação (Chaves Alvarez, 1988).

Os governos que sucedem a Paz Estenssoro entre 1989 e 2002 são expressivos das fases de aprofundamento e crise das reformas por ele iniciadas. A presidência de Jaime Paz Zamora (1989-93), do Movimiento de Izquierda Revolucionaria (MIR), tem como marca importante uma maior abertura frente às comunidades indígenas, que se materializa no reconhecimento da propriedade de terras de origem ancestral no oriente do país e o atendimento de reivindicações contra a exploração de recursos naturais por 
empresas estrangeiras em territórios de etnias quéchuas e aimarás. A primeira administração de Gonzalo Sanchez de Lozada (1993-1997) representa o momento culminante da implementação do modelo neoliberal, com uma aposta ambiciosa em reformas que avançam da economia ao sistema político. Conforme destaca Alfredo Camargo, seu programa Plan de Todos promovia

a capitalização de empresas estatais, que encerraria o ciclo do Estado-empresário, herança econômica da Revolução de 1952; a descentralização administrativa e a ampliação da capilaridade do Estado, mediante a lei de Participação Popular; e, por fim, a Reforma Educativa (2006, p. 183).

Algumas das mudanças promovidas pelo governo têm incidência na inserção política e econômica das populações indígenas. A Lei de Participação Popular aumenta o número de municípios e o repasse de recursos sob sua responsabilidade direta. Além de "ampliar a capilaridade do Estado no meio rural - um dos seus objetivos imediatos -, a Lei abriu espaços para que lideranças indígenas assumissem, pela via eleitoral, o controle das suas comunidades, processo iniciado nas eleições de 1995" (Camargo, 2006, p. 186). A reforma constitucional de 1994 inclui o reconhecimento do caráter multiétnico e pluricultural do país e da propriedade comunitária indígena, através da criação das Terras Comunitárias de Origem. A reforma educativa introduz questões como a interculturalidade e o bilinguismo, na perspectiva de promover um sistema educacional que contemple a diversidade étnica e cultural do país. Na sua formulação, teve papel fundamental o vice-presidente Victor Hugo Cárdenas, líder do Movimiento Revolucionario Tupac Katari de Liberación (MRTKL), e até esse momento o indígena a ocupar o cargo mais alto no Estado boliviano. 
No início dos anos 1970, especialmente durante o breve governo de Juan José Torres, emergem novas lideranças sindicais camponesas, que passam a ser conhecidas como kataristas, pela sua identificação com Tupac Katari, rebelde aimará que comandou o cerco à cidade de La Paz em 1780 com um exército de 40 mil indígenas. De acordo com Hervé Do Alto, "a reforma agrária e o acesso à educação pública permitiram aos camponeses construir laços de sociabilidade no âmbito urbano, conservando, no entanto, o vínculo com seu mundo rural de origem”. Nesse contexto, surgem quadros capazes de

teorizar o sentimento de frustração gerado pela situação de "desclassamento" sofrida por seus membros e, através dos vínculos mantidos com o mundo rural, atuar neste como empresários de politização capazes de construir e difundir um discurso que outorgue coerência e um sentido político a esta experiência social (2007, p. 29) ${ }^{5}$.

O katarismo teve desdobramentos diversos na política boliviana, sendo referência de correntes de esquerda que adotaram a luta armada, como o Ejército Guerrillero Tupac Katari (EGTK), comandado por Felipe Quispe e no qual militou Álvaro García Linera, vice-presidente de Evo Morales, e mais moderadas, como o MRTKL de Victor Hugo Cárdenas.

Num momento ascendente da agenda liberalizante, Cárdenas percebe sua ida ao poder executivo como expres-

\footnotetext{
${ }^{5}$ Referindo-se ao mesmo processo, Garcia Linera destaca a repercussão, a partir dos anos 1970, da ampliação do acesso à educação pública promovida pela Revolução de 1952, com a ação de uma intelectualidade aimará migrante. "Estes intelectuais, em círculos políticos autônomos ou em pequenas empresas culturais (futebol, os programas de rádio, palestras nas praças etc.), vão construindo, entre dirigentes de sindicatos agrários, redes de comunicação e de releitura da história, a língua e a etnicidade que começam a disputar a legitimidade dos discursos campesinistas com os quais o Estado e a esquerda convocavam ao mundo indígena" (Monasterios e Stefanoni, 2007, p. 155).
} 
são de novos tempos de abertura do sistema político boliviano às maiorias indígenas historicamente excluídas. Em entrevista ao New York Times, destaca como sua responsabilidade

mostrar que estamos abrindo um caminho para criar uma sociedade que pode ser chamada verdadeiramente de democrática. Isso faz parte de um despertar do movimento indígena. E é a expressão de algo normal, que os povos indígenas também devem ser capazes e autorizados a governar (Cárdenas apud Nash, 1993).

A fase ofensiva das reformas se encerra com a conclusão da primeira administração de Sánchez de Lozada, seu grande idealizador e promotor. O sucessor, Hugo Banzer (que falece de câncer em 2001, cujo mandato foi concluído pelo vice, Jorge Quiroga), enfrenta um contexto de forte mobilização popular, pautando sua ação pela resposta defensiva às crescentes reações contra os efeitos sociais regressivos das reformas.

A lógica do modelo implementado tinha um componente estabilizador contra a hiperinflação, de reforma do Estado e austeridade fiscal, apontava para um perfil exportador em que se destacam a soja e o gás, favorecia algumas regiões, como a de Santa $\mathrm{Cruz}^{6}$. Apesar do controle da inflação e crescimento anual de $4 \%$ em meados dos anos 1990, há um forte retrocesso a partir de 1997, em que pesam as crises financeiras que atingem os países vizinhos (marcadamente Brasil e Argentina), dos quais o comércio exterior boliviano é fortemente dependente, e os efeitos nas comunidades camponesas das políticas de erradicação da coca acordadas com Estados Unidos. Entre 1997 e 2002, o PIB per capita passa de 1.100 a 890 dólares (Crabtree, 2006).

\footnotetext{
${ }^{6}$ Conforme dados da Cámara de Industria y Comercio (Cainco), atualmente Santa Cruz "origina $30 \%$ do PIB nacional, gera $62 \%$ das divisas do país, produz $50 \%$ das exportações e recebe $47,6 \%$ do investimento estrangeiro que chega a Bolívia" (Stefanoni, 2007, p. 42).
} 
Sem cumprir satisfatoriamente as promessas de crescimento, as políticas aplicadas contribuem para acentuar a desigualdade social num país em que dois terços da população vive abaixo da linha da pobreza. De acordo com Crabtree, cálculos da Unidad de Análisis de Políticas Sociales y Económicas (Udape), entidade fortemente influente nas políticas sociais do governo boliviano, apontavam ser necessário um crescimento anual sustentado de $7 \%$ para que o desempenho dos setores mais dinâmicos da economia contribui-se decisivamente para a diminuição da pobreza. Conforme mostra a Cepal, a tendência do coeficiente de Gini apresenta uma evolução negativa, de 0.538 em 1989, para 0.586 em 1999 e 0.614 em 2002 (2007, p. 79). Em termos geográficos, regiões como Santa Cruz, Tarija e Oruro aumentaram sua participação no PIB nacional, ao contrário de Cochabamba e La Paz.

Nesse contexto, processa-se um novo fenômeno mi196 gratório interno que vai ter como protagonistas importantes os trabalhadores desempregados, especialmente das minas, que se dirigem para as cidades e para áreas de colonização agrícola. Pelos seus impactos políticos posteriores nos movimentos que estarão na vanguarda da ascensão das novas lideranças que convergem no governo de Evo Morales, cabe destacar dois exemplos emblemáticos: no âmbito da migração para as cidades, o crescimento de El Alto, situada a nordeste de La Paz, que obtém a categoria de cidade em 1988, passara de 95 mil habitantes em 1976 para mais de 800 mil em 2006; em termos da migração para áreas agrícolas, a expansão da economia da folha de coca na região do Chapare, no Departamento de Cochabamba, cuja população passa de 25 mil habitantes no início da década de 1970 para mais de 187 mil no censo de 2001.

É nessa região que a família de Evo Morales se estabelece em 1980, passando a dedicar-se ao plantio da folha 
de coca, e onde ele inicia suas atividades como sindicalista. O movimento cocaleiro destaca-se pela sua capacidade para combinar o combate às políticas de erradicação promovidas pelos governos boliviano e estadunidense ${ }^{7}$, pela invocação de valores culturais do mundo andino, e pela incorporação da experiência organizativa do sindicalismo operário, do qual se origina boa parte dos seus militantes. Conforme destaca Hervé Do Alto (2007, p. 36), “os cocaleiros reformulam a clivagem nação/antinação, que estrutura a ideologia nacionalista revolucionária, adaptando-o ao seu próprio contexto especialmente ao fazer da coca um elemento próprio da cultura boliviana agredida pelo imperialismo".

A precarização do quadro econômico e social vai minando a credibilidade das reformas. Cabe destacar dois processos que conseguiram demarcar os limites ao avanço da agenda de liberalização, atingindo a privatização dos recursos naturais, um dos seus objetivos importantes. Em 2000, o movimento contra a atribuição à empresa Bechtel do direito exclusivo de comercializar e distribuir o sistema de água de Cochabamba obriga o governo Banzer a cancelar a concessão. Em 2003, um ano após o início do seu segundo mandato, Sanchez de Lozada, eleito com 22,46\% dos votos, contra 20,94\% de Evo Morales, propõe a exportação de gás para México e Estados Unidos através do Chile. Desencadeia-se um levante popular que envolve greves, paralisação de estradas, manifestações, com apoio de organizações camponesas, da COB e partidos de esquerda, que se radicaliza frente à forte repressão lançada pelo presidente, forçado a renunciar. As duas mobilizações contaram com a liderança dos sindicatos de camponeses plantadores de coca e das comunidades do El Alto, plasmadas por uma

\footnotetext{
${ }^{7}$ De acordo com dados apresentados por Vivian Urquidi (2007), a erradicação promoveu uma diminuição da população no Chapare de 70 mil famílias em meados dos anos 1990 para 40 mil em 2000.
} 
identidade indígena que passa a constituir-se como eixo central da política boliviana ${ }^{8}$.

Na Guerra do Gás, os movimentos populares recebem forte apoio do parlamento, que conta com a representação de partidos que expressam essa nova dinâmica sociopolítica do país, com destaque para o Movimiento Indígena Pachakuti (MIP), fundado em 2000, dirigido por Felipe Quispe Huanca, e o Movimiento al Socialismo (MAS), fundado em 1997, liderado por Evo Morales. Ambos os partidos obtiveram 28\% dos votos nas eleições de 2002, elegendo "36 parlamentares, número que, somado ao dos deputados de militância indígena eleitos por outras agremiações, eleva a representação parlamentar indígena a 52 (em total de 130 deputados e 27 senadores)" (Camargo, 2006, p. 12).

Em todo esse processo, revelam-se duas grandes tendências: 1) a falência das políticas econômicas aplicadas a 198 partir de 1985 ; 2) a mudança no perfil dos movimentos sociais, em que a lógica classista que predominou até os anos 1980, com a liderança da COB e de forte presença no setor mineiro-exportador centrado no estanho, cede espaço para organizações camponesas que assumem uma identidade indígena.

Sánchez de Lozada é substituído pelo vice-presidente, Carlos Mesa, que não resiste às constantes pressões populares cobrando um maior nacionalismo em relação às empresas estrangeiras que exploram os recursos energéticos do país, e renuncia em junho de 2005. Seu cargo é exercido provisoriamente pelo presidente da Corte Suprema de Jus-

\footnotetext{
${ }^{8}$ Conforme aponta Luis Tapia, "O elemento índio na Bolívia é algo plural, heterogêneo, que se reflete no oriente e no altiplano em formas próprias de organização e de governo que não foram eliminadas durante a Colônia nem na República e que hoje são o suporte organizativo da mobilização dos sindicatos agrários" (2005, p. 348).
} 
tiça, Eduardo Rodríguez, até a pose de Evo Morales, eleito por ampla maioria de votos no mês de dezembro.

\section{O governo de Evo Morales}

No programa eleitoral do MAS se destacam três propostas estreitamente vinculadas às lutas dos anos recentes: convocação de uma Assembleia Constituinte, nacionalização dos hidrocarbonetos, defesa do cultivo e industrialização da coca. Transcorridos três anos de mandato, as principais medidas tomadas permitem estabelecer uma correlação entre a postura de Morales na oposição e no exercício do governo.

Em julho de 2006, é eleita a Assembleia Constituinte, com mandato de um ano para redigir a nova carta. Embora contando com a maioria dos deputados, o governo não consegue atingir os dois terços requeridos para a aprovação de mudanças sem negociar com outras forças políticas, o que levou o MAS a propor que as decisões fossem por maioria simples, gerando fortes disputas com a oposição, frente as quais acabou cedendo. No dia primeiro de maio, é decretada a nacionalização dos hidrocarbonetos, com o envio de tropas militares e funcionários da empresa estatal Yacimientos Petrolíferos Fiscales Bolivianos (YPFB) para ocupar as instalações petrolíferas e os postos de gasolina. O decreto passa a obrigar todas as empresas a se tornarem sócias da YPFB, que se torna proprietária de $51 \%$ das ações, e a renegociar os contratos sobre a distribuição dos lucros, aumentando a parcela que vai para o Estado. Apesar das reações iniciais negativas dos setores afetados, que incluem a brasileira Petrobras, consegue-se renegociar os contratos em condições favoráveis, com ganhos imediatos de arrecadação, que contribuem para um superávit fiscal de $6 \%$ em 2006, após anos de déficits recorrentes. No que concerne à economia da coca, o governo iniciou gestões na Junta Interamericana de Fiscalização de Entorpecentes para obter a 
despenalização do plantio da folha, dentro de uma estratégia que busca ampliar a produção e exportar produtos industriais derivados desta, como farinha e medicamentos, para o qual prevê uma expansão das áreas de plantio de 12 mil para 20 mil hectares. Em outubro de 2007, o presidente anuncia a criação do bônus Renta Dignidad, assinação vitalícia de 26 dólares mensais para todas as pessoas de mais de sessenta anos a ser financiado pelo recorte de $30 \%$ da renda petroleira dos Departamentos produtores, gerando forte reação por parte dos governadores afetados.

As medidas implementadas por Morales buscam gerar benefícios tangíveis e não conjunturais para os setores mais pobres da população, como forma de dar sustentabilidade à nova correlação de forças e reduzir os espaços para opções conservadoras que busquem retomar as trajetórias do passado. Esse quadro abre para as elites tradicionais duas possibilidades, a insistência na ruptura separatista presente nas 200 propostas de autonomia dos Departamentos da chamada Meia Lua (Santa Cruz, Tarija, Pando e Beni), ou a busca de uma estratégia de convivência permanente baseada numa agenda que legitime o pluralismo, especialmente no âmbito do sistema econômico e do regime de propriedade.

$\mathrm{Na}$ perspectiva de analistas da esquerda críticos do MAS, a segunda possibilidade seria viável, dado que se trata de um governo que compartilha com os anteriores "o mesmo respeito pelas estruturas fundamentais do capitalismo" (Orellana Aillón, 2006, p. 46). De acordo com essa visão, estaríamos frente a um processo de modernização, com ampliação da cidadania e democratização do acesso ao Estado, que passa a reconhecer os indígenas como tais, em que as lutas entre governo e oposição não seriam insolúveis, há espaço para um

pacto social entre a antiga oligarquia, o imperialismo e uma nova burocracia estatal que [...] não romperia com o 
regime de acumulação imperante, senão que daria oxigênio ao já existente, ao realizar certas reformas nacionalistas que redistribuam o excedente econômico proveniente dos hidrocarbonetos e consolidem a adesão das massas ao novo governo por um tempo mais longo do que os lapsos políticos que temos conhecido nos últimos anos (Orellana Aillón, 2006, p. 52).

Nessa linha de argumentação, os ímpetos transformadores do MAS teriam destino similar aos do MNR na revolução de 1952, ao conformar uma nova força cuja ascensão garante fôlego a uma futura restauração oligárquica. Certamente não é essa a perspectiva com que o governo encara os desafios de operar seu programa de mudanças num quadro de governabilidade amparado na legalidade institucional. Ao discutir o significado da democracia comunitária, que estaria no horizonte da renovação constitucional apresentada por Evo Morales, o vice-presidente Garcia Linera destaca o desencontro histórico entre um Estado monocultural, fundado na etnia branca, a língua espanhola, a democracia liberal e o mercado capitalista, e uma sociedade multicultural de diferentes etnias e formas de organização política e econômica ${ }^{9}$. Para ele,

O Estado, como síntese, deveria ser uma institucionalidade capaz de articular, de compor uma engenharia política formada por uma presença proporcional das culturas e identidades linguísticas, além de umas instituições modernas e tradicionais, deliberativas, representativas, e assembleísticas na toma de decisões a escala geral, "nacional" (Garcia Linera, 2006a, pp. 81-82).

\footnotetext{
${ }^{9}$ De acordo com os dados do Censo Nacional de 2001, 62\% dos bolivianos maiores de idade identificam sua ascendência a povos indígenas e a língua materna de pouco mais de $40 \%$ da população é de um idioma indígena (Godio, 2006, p. 353-354).
} 
A ideia de síntese, como processo integrador da diversidade, é componente essencial do "evismo", termo utilizado por Garcia Linera para caracterizar uma estratégia de poder que se diferencia da esquerda tradicional, em que destaca cinco peculiaridades: 1) Na relação com a representação política no plano do Executivo e Legislativo, os movimentos sociais não operam "como base, senão como atores diretos que avançam da resistência para a expansão e controle de postos no Estado" (2006b, p. 26). 2) Em termos discursivos, articula um indianismo cultural de natureza ampla e flexível, que vai além da ascendência aimará do seu líder principal, que "pode abrir-se aos mestiços, aos brancos ou a quem seja, porém sob a premissa de organizar um novo projeto que tenha como base outra vez a nação" (2006b, p. 27). 3) Diferentemente do nacionalismo que deu origem aos movimentos revolucionários do passado, centrados nas classes médias, especialmente seus setores ilustrados, "aqui a ideia 202 de nação recai nos índios que vêm dos sindicatos agrários e camponeses" (2006b, p. 28). 4) Sua base econômica está nos recursos naturais sob controle do Estado, da "pequena produção, os microempresários, os artesãos, as comunidades, os camponeses" (2006b, p. 28).5) Não segue a tradição das revoluções sociais que operaram rupturas estruturais no modo de produção e na organização estatal, mas aponta para uma revolução política, cultural, descolonizadora, "que abre espaços de representação, modifica as estruturas de poder, modifica a composição das elites de poder e os direitos, e com isso, as instituições do Estado" (2006b, p. 31).

Sem descartar o socialismo como perspectiva estratégica, Linera considera que as condições socioeconômicas que vigoram no país comprometem sua viabilidade nas próximas décadas. Nesse sentido, aponta na direção de um novo modelo, que denomina capitalismo andino-amazônico, pautado pela "construção de um Estado forte, que regule a expansão da economia industrial, extraia 
seus excedentes e os transfira ao âmbito comunitário para potenciar formas de auto-organização e de desenvolvimento mercantil propriamente andino e amazônico" (Garcia Linera, 2006c). Em entrevista a Maristella Svampa e Pablo Stefanoni, aponta os avanços registrados na ampliação da presença do Estado na economia a partir da posse do governo, que passa de " 6 ou $7 \%$ do Produto Interno Bruto [...] a 19\%. Nosso objetivo é chegar a 30\%” (Linera apud Svampa e Stefanoni, 2007, p. 149).

Entre as razões que dificultam na atualidade o caminho ao socialismo, destaca duas:

Por um lado existe um proletariado minoritário demograficamente e inexistente politicamente; e não se constrói socialismo sem proletariado. Segundo: o potencial comunitarista agrário e urbano está muito debilitado. [...] O potencial comunitário que vislumbraria a possibilidade de um regime comunitarista socialista passa, em todo caso, por potenciar as pequenas redes comunitaristas que ainda sobrevivem e enriquecê-las. Isto permitiria, vinte ou trinta anos, poder pensar numa utopia socialista (Garcia Linera, 2006c).

Apesar de reconhecer o significado histórico das mudanças propostas pelo governo de Evo Morales, especialmente seu projeto de Estado-multicultural e multinacional, Anibal Quijano receia das possibilidades de convívio permanente entre formas diferentes de administrar o capital ou conceber a riqueza e os recursos naturais no âmbito do capitalismo andino-amazônico: "Pode a redistribuição multicultural e/ou multinacional do controle do Estado ocorrer separadamente da redistribuição do controle do trabalho, dos seus recursos e dos seus produtos, e sem mudanças igualmente profundas nos outros âmbitos básicos do padrão de poder?" (Quijano, 2006, p. 18). 
Na perspectiva do governo, a Assembleia Constituinte é o fórum em que se processa a formulação do novo Estado, a partir de negociações com a oposição em torno das pautas de integração dos vários mundos que compõem a diversidade nacional. No entanto, como analisaremos na próxima seção, as tendências que predominam ao longo da Constituinte colocam em relevo os receios expressos por Quijano.

\section{0 processo constituinte e a escalada de conflitos}

Após diversas postergações e impasses, dado o boicote dos congressistas da oposição, apoiados por seis dos nove governadores departamentais, incluindo os quatro da Meia Lua, Cochabamba e La Paz, a nova Constituição é aprovada em duas votações. Em 9 de dezembro de 2007, é submetido o texto completo sem destaques e, em 3 de fevereiro de 2008, são votados os artigos separadamente, recebendo

204 maioria favorável de dois terços dos constituintes presentes na votação, já que o principal partido oposicionista, Poder Democrático y Social (Podemos), que detém maioria no Senado, não participou em nenhum dos processos.

Para entrar em vigor, a carta passou por referendo em 25 de janeiro de 2009, após acordo entre o governo e a oposição que, além das discordâncias de conteúdo, questionava a legalidade do texto aprovado sem a sua presença. No plano legal, o principal argumento era que a regra vigente determinava que a aprovação devesse contar com o mínimo de dois terços do total dos congressistas, alterada pelos que participaram na seção; no plano do conteúdo, os alvos principais eram a reeleição presidencial, as autonomias indígenas e a reforma agrária, temas que trataremos na próxima seção. Como resultado, o Podemos e os governadores dos departamentos de Santa Cruz, Tarija, Beni, Pando e Chuquisaca iniciaram um movimento de desobediência civil. 
Consciente das dificuldades, em janeiro de 2008 o presidente propõe aos governadores o inicio de negociações na perspectiva de gerar um acordo nacional que dê saídas institucionais para a crise política. Entre os temas da agenda colocados em debate destacam-se a unidade nacional, a democracia, a legalidade, a estatização da economia, as autonomias departamentais, o bônus Renta Dignidad, o respeito à propriedade privada e a iniciativa do Executivo de realizar um referendo revocatório que inclua, além do mandato presidencial, o dos nove governadores.

Essa última proposta é anunciada pelo governo como saída democrática capaz de reiniciar, com nova legitimidade, as relações entre as partes em conflito. Realizado em agosto, o mandato do presidente recebe a aprovação de mais de $67 \%$ do eleitorado. Por outro lado, os governadores opositores obtêm resultados favoráveis em Santa Cruz, Beni, Tarija e Pando, perdendo em Cochabamba e La Paz.

O novo quadro não altera a situação de conflito, ao contrário, os governos da oposição partem para o confronto, adotando iniciativas separatistas de caráter unilateral. Como parte desse processo, adquire crescente visibilidade a controversa postura da embaixada estadunidense, com ostensiva intervenção em assuntos internos do Estado boliviano, que compromete as relações entre os dois países.

Em junho de 2008, a atuação da United States Agency for International Development (Usaid) foi seriamente questionada por movimentos sociais na região do Chapare, que decidiram em assembleia expulsar seus funcionários, sob a acusação de promover ações contra o governo de Evo Morales, que saudou a decisão do movimento. Entre as denúncias, destaca-se o apoio à organização separatista de Santa Cruz, Unión Juvenil Cruceñista, espionagem e assessoria aos governos de oposição (Ochoa, 2008).

As tensões diplomáticas entre Bolívia e Estados Unidos atingiram um ponto crítico com a expulsão do embaixador 
Philip Goldberg em setembro de 2008, acusado pelo presidente boliviano de liderar o processo separatista promovido pelos governos de Santa Cruz, Pando, Beni e Tarija, que organizam referendos a revelia do Executivo. Sua curta estância no país, iniciada em agosto de 2006, esteve marcada por diversos incidentes que colocaram sob suspeita os objetivos estadunidenses.

Em agosto de 2007, o ministro da Presidência, Juan Ramon Quintana, denunciou o envio de ajuda por parte da Usaid para setores oposicionistas, sob a justificativa de apoiar programas destinados a "restabelecer a democracia no país”, conforme documentos da agência por ele citados (Reuters, 2007). Em fevereiro de 2008, são divulgadas pela imprensa revelações de cidadãos estadunidenses sobre duas tentativas da embaixada na Bolívia de envolvê-los em ações de espionagem: em julho de 2007, um grupo de trinta voluntários dos Corpos de Paz recebeu orientação do 206 funcionário de segurança da embaixada, Vincent Cooper, para que observassem e relatassem as atividades de cubanos e venezuelanos que encontrassem durante sua estada no país; em novembro, o mesmo funcionário fez solicitação similar a bolsista da Fundação Fulbright. Essas revelações levaram o presidente a declarar Cooper persona non grata. A embaixada reconheceu o incidente e informou que ele não retornaria à Bolívia (Friedman-Rudovsky e Ross, 2008). O ponto de ruptura foi provocado pela reunião de Goldberg com o governador de Santa Cruz, Rubén Costas, em agosto de 2008, que coincidiu com o processo de radicalização da atuação oposicionista, fortemente personificada na figura desse dirigente, que dias antes tinha proferido um discurso fortemente ofensivo contra Evo Morales, e culminou na expulsão do diplomata ${ }^{10}$.

\footnotetext{
${ }^{10}$ Em conferência de imprensa, ao agradecer o apoio internacional recebido para enfrentar a crise com a oposição, Evo Morales se referiu ao discurso de Costas e ao
} 
A escalada de confrontos violentos em setembro, com crescente número de vítimas fatais no Departamento de Pando, declarado sob estado de sítio, leva a então presidente chilena Michelle Bachelet a convocar reunião de emergência da União das Nações Sul-americanas (Unasul), em que os chefes de Estado manifestam seu apoio a Evo Morales e chamam ao fim das hostilidades contra um presidente democraticamente eleito.

Em outubro se inicia o processo de negociações entre governo e oposição, que conta com a participação, como testemunhas, de representantes da OEA, da Igreja Católica, da Unasul, da ONU e da União Europeia. Com o aval do Congresso nacional, chega-se a um acordo para a realização do referendo em 25 de janeiro de 2009. Em duas votações separadas, submete-se à consulta a definição do tamanho máximo da propriedade da terra, entre as opções de 5 mil ou 10 mil hectares, em que a primeira recebe $80 \%$ dos votos, e um novo texto constitucional em que são reformulados cem artigos, aprovado por $61 \%$ dos votantes. O presidente Evo Morales ganha legitimidade, com manifestações favoráveis que incluem o governo de Barack Obama, expressas pelo porta-voz do Departamento de Estado, Robert Wood, que parabenizou o povo boliviano pelo referendo, sinalizando para a melhoria das relações bilaterais.

No quadro 1, são apresentados, de forma comparativa, artigos selecionados do texto original e do que foi a votação no referendo.

posterior encontro com Goldberg: "O [caso] do embaixador de Estados Unidos é muito grave. Se reuniu de maneira reservada com um prefeito que me trata de animal, de mono, de macaco, de incapaz e de excelentíssimo assassino" (Morales apud Diário CoLatino, 2008). 


\section{Quadro 1}

Mudanças na Constituição acordadas entre governo e oposição

\section{Texto aprovado pela Assembleia Constituinte}

Artigo 3. 0 povo boliviano está conformado pela totalidade das bolivianas e dos bolivianos pertencentes às áreas urbanas, de diferentes classes sociais, às nações e povos indígenas originários camponeses, e às comunidades interculturais e afro-bolivianas.

Artigo 7. A soberania reside no povo boliviano e se exerce de forma direta; é inalienável, intocável, indivisível, imprescritível e indelegável, e dela emanam as funções e atribuições do poder público.

Artigo 30. Seção 17. (Estabelece o direito) À gestão territorial indígena autônoma, e ao uso e aproveitamento exclusivo dos recursos naturais renováveis existentes em seu território.

\section{Texto modificado e aprovado no referendo}

Artigo 3. A nação boliviana está conformada pela totalidade das bolivianas e dos bolivianos, as nações e povos indígenas originários camponeses, e as comunidades interculturais e afro-bolivianas que em conjunto constituem o povo boliviano.

Artigo 7. A soberania reside no povo boliviano, se exerce de forma direta e delegada. Dela emanam, por delegação, as funções e atribuições dos órgãos do poder público; é inalienável e imprescritivel.

Artigo 30. Seção 17. (Estabelece o direito) À gestão territorial indígena autônoma, e ao uso e aproveitamento exclusivo dos recursos naturais renováveis existentes em seu território sem prejuízo dos direitos legitimamente adquiridos por terceiros.

Artigo 45. Todas as bolivianas e os bolivianos têm direito à seguridade social. gratuito.

Artigo 57. A expropriação se imporá por causa de necessidade ou utilidade pública, ou quando a propriedade não cumpra uma função social, qualificada conforme com a lei e prévia indenização justa.

Artigo 93. Seção 3. A educação superior está conformada pelas universidades, as escolas superiores de formação docente, e os institutos técnicos, tecnológicos e artísticos.

\footnotetext{
Artigo 273. 0 regime autonômico implica a eleição direta das suas autoridades pelas cidadãs e os cidadãos, e as faculdades legislativas normativo-administrativa, fiscalizadora, executiva e técnica, exercidas pelas entidades autônomas no âmbito da sua jurisdição e competências exclusivas.
}

Artigo 310. Seção 2. Administrar os serviços públicos, diretamente ou por meio de empresas público-comunitárias.
Artigo 57. A expropriação se imporá por causa de necessidade ou utilidade pública, qualificada conforme com a lei e prévia indenização justa. A propriedade imobiliária urbana não está sujeita a reversão.

Artigo 93. Seção 3. A educação superior está conformada pelas universidades, as institutos técnicos, tecnológicos e artísticos, fiscais e privados.

Artigo 273. A autonomia implica a eleição direta das suas autoridades pelas cidadãs e os cidadãos, a administração dos seus recursos econômicos, e o exercício das faculdades legislativa, regulamentária, fiscalizadora e executiva, pelos seus órgãos de governo autônomo no âmbito da sua jurisdição e competências e atribuições.

Artigo 310. Seção 2. Administrar os serviços básicos de água potável e esgoto diretamente ou por meio de empresas públicas, comunitárias, cooperativas ou empresas mistas. escolas superiores de formação docente, e os 


\begin{abstract}
Artigo 351. Seção 1. 0 Estado, a través de entidades públicas, sociais ou comunitárias, assumirá o controle e a direção sobre a prospecção e exploração, industrialização, transporte e comercialização dos recursos naturais.

Seção 2. 0 Estado poderá subscrever contratos de associação de economia mista com pessoas jurídicas, bolivianas ou estrangeiras, para 0 aproveitamento dos recursos naturais. Devendo se assegurar 0 reinvestimento das utilidades econômicas no país.

Seção 3. A gestão e administração dos recursos naturais se realizarão garantindo o controle e a participação social na tomada de decisões. Na gestão e administração poderão estabelecer-se entidades mistas, com representação estatal e da sociedade, e se precaverá o bem-estar coletivo.
\end{abstract}

Artigo 394. Seção 1. A propriedade agrária individual classifica-se em pequena e empresarial, em função da superfície, da produção e os critérios de desenvolvimento.

Suas extensões máximas e mínimas, características e formas de conversão serão regulamentadas por lei.

Seção 2. A pequena propriedade é indivisivel, constitui patrimônio familiar intocável, e não está sujeita ao pagamento de impostos à propriedade agrária. A indivisibilidade não afeta o direito à sucessão hereditária nas condições estabelecidas por lei. Seção 3. O Estado reconhece, protege e garante a propriedade comunitária ou coletiva, que compreende o território indígena originário camponês, as comunidades interculturais originárias e das comunidades camponesas. A propriedade coletiva se declara indivisivel, imprescritível, intocável, inalienável e irreversível e não está sujeita ao pagamento de impostos à propriedade agrária. As comunidades poderão ser tituladas reconhecendo a complementaridade entre direitos coletivos e individuais respeitando a unidade territorial com identidade.
Artigo 351. Seção 1. 0 Estado, assumirá o controle e a direção sobre a prospecção, exploração, industrialização, transporte e comercialização dos recursos naturais estratégicos a través de entidades públicas, cooperativas ou comunitárias, as que poderão por sua vez contratar empresas privadas e constituir empresas mistas.

Seção 2. 0 Estado poderá subscrever contratos de associação com pessoas jurídicas, bolivianas ou estrangeiras, para 0 aproveitamento dos recursos naturais.

Devendo assegurar-se o reinvestimento das utilidades econômicas no país.

Seção 3. A gestão e administração dos recursos naturais se realizará garantindo o controle e a participação social no desenho das políticas setoriais. Na gestão e administração poderão estabelecer-se entidades mistas, com representação estatal e da sociedade, e se precaverá o bem-estar coletivo.

Seção única. A propriedade agrária individual classifica-se em pequena, mediana e empresarial, em função da superfície, da produção e dos critérios de desenvolvimento. características e formas de conversão serão regulamentadas por lei. Garantemse os direitos legalmente adquiridos por proprietários particulares cujos prédios se encontrem localizados ao interior de territórios indígena originário camponeses.

Fonte: Repac (2009). 


\section{Um Estado Plurinacional}

se chegamos aonde chegamos como presidente, ministros, parlamentares que vêm fundamentalmente dos povos indígenas originários, queremos lhes dizer, não viemos com a vingança, chegamos aqui para a esperança do povo boliviano" (Morales, 2006, p. 104).

No seu artigo 1, a Constituição boliviana propõe uma nova forma de Estado, buscando expressar a diversidade nacional:

Bolívia se constitui num Estado Unitário Social de Direito Plurinacional Comunitário, livre, independente, soberano, democrático, intercultural, descentralizado e com autonomias. Bolívia funda-se na pluralidade e o pluralismo político, econômico, jurídico, cultural e linguístico, dentro

210 do processo integrador do país (NCPE, 2009, p. 13).

No plano do poder executivo, instaura-se a reeleição do presidente. No que diz respeito à organização territorial, é instituída uma divisão entre departamentos, províncias, municípios e territórios indígenas originários camponeses, com autonomias de escolha de autoridades e administração.

De acordo com a Constituição, considera-se "nação e povo indígena originário camponês a toda coletividade humana que compartilhe identidade cultural, idioma, tradição histórica, instituições, territorialidade e cosmovisão, cuja existência é anterior à invasão colonial espanhola" (NCPE, 2009, p. 22). Adota-se aqui uma perspectiva culturalista em que o indígena não se define por essencialismos de raça ou pertencimento às etnias predominantes, especialmente a aimará e quéchua, mas por identidades construídas, sem limites preestabelecidos em termos inclusivos. A dimensão nacional é reforçada nas alterações do artigo 
3, conforme expostas no quadro 1, em que a categoria povo passa a ser subordinada à de nação e a referência explícita a classes sociais é eliminada.

Como vimos, o tema das autonomias nos territórios indígenas originários camponeses é um dos grandes geradores de impasses com os governadores da oposição na aprovação do texto original da Constituição, que perceberam a incorporação de novas jurisdições à estrutura interna dos departamentos como limitações ao seu poder. A diversidade de concepções sobre a propriedade, a utilização da terra e seus recursos, num regime que estabelece instâncias superpostas na capacidade de legislar e administrar a justiça abre possibilidades de geração de conflitos entre poderes legítimos, já que os mesmos direitos de usufruto poderão ser reivindicados pelas diversas partes.

O quadro 1 apresenta algumas das mudanças negociadas nos temas das autonomias territoriais indígenas, as formas de propriedade e os alcances das reformas que impliquem na sua reestruturação. No artigo 7, estabelece-se uma alteração na caracterização da soberania, no qual o exercício direto, presente na tradição indígena e que vigora nas comunidades, ao qual se atribuía o caráter indelegável, passa a incorporar a forma delegada da tradição republicana. No artigo 30 , sobre o uso dos recursos naturais não renováveis, é feito um acréscimo que garante direitos já adquiridos de terceiros. No artigo 273, elimina-se a exclusividade na jurisdição e competências das entidades autônomas. No caso da reforma agrária, o artigo 394 garante "os direitos legalmente adquiridos por proprietários particulares cujos prédios se encontrem localizados no interior de territórios indígenas originários camponeses", modificação que, além de limitar a autonomia, elimina o efeito retroativo da redistribuição de terras, preservando as grandes propriedades existentes. O direito adquirido é também aplicado aos imóveis urbanos, conforme o artigo 57. 
No âmbito da estrutura econômica, define-se um modelo de caráter plural, em que convivem, com igualdade jurídica perante a lei, formas de organização comunitária, estatal, cooperativa, mista e privada. Em outros artigos, as mudanças acordadas ampliam a presença dos setores cooperativo, misto e privado, seja no âmbito da educação (artigo 93), administração dos serviços públicos e organização econômica do Estado (artigos 310 e 351), e eliminam a exclusividade do serviço gratuito (artigo 45).

Retomando as análises conflitantes sobre o perfil do governo de Evo Morales, pode-se afirmar que a perspectiva oficial pauta-se por uma abordagem multiculturalista, sustentada no respeito à autonomia e à pluralidade dos modos de vida que compõem a nacionalidade boliviana. A partir desse contexto mais amplo, são delimitados espaços de mudança nas relações de propriedade, na perspectiva de um capitalismo que reconheça e legitime diversas formas 212 de apropriação da riqueza.

Certamente, a estratégia evista se afasta da lógica da revolução social ancorada na luta de classes, mas isso não significa que estejamos frente a uma versão atualizada da restauração oligárquica pós-1952, em que o MAS protagonizaria papel similar ao do MNR. O processo de conflitos e acordos que levou à aprovação da Carta Constitucional mostra a difícil arquitetura de um novo Estado que contemple, num regime de democracia representativa, a convivência de diversidades nem sempre reconciliáveis.

Em termos conjunturais, a Constituição referendada expressa uma determinada correlação de forças, em termos estruturais, estabelece os marcos legais de um processo de mudanças de longo alcance. A estratégia multiculturalista do evismo, legitimada em dois referendos por mais de $60 \%$ dos votantes, se enraíza na mentalidade de uma população majoritariamente pobre, que reivindica a indianidade e vislumbra espaços indeterminados de ampliação 
do seu poder, levando ao recuo das alternativas golpistas de uma minoria economicamente dominante, mas cujos recursos políticos estão em retração. Como vimos, o radicalismo da oposição tem encontrado limites não apenas na reação dos setores de apoio ao governo, mas dos países vizinhos e organizações internacionais em favor do respeito à legalidade institucional, influenciando decisivamente na construção de acordos que viabilizem a governabilidade. Dentro desse quadro, o direcionamento das mudanças tende a acompanhar a interação entre as ações do governo e as expectativas e reivindicações dos setores populares, partidos e movimentos sociais.

Num cenário consolidado de estabilidade institucional, criam-se condições estruturais de viabilidade para o modelo de desenvolvimento proposto pelo governo: um "Estado Unitário Social de Direito Plurinacional Comunitário que expresse jurídica e politicamente as relações sociais do "capitalismo andino-amazônico". Num cenário externo que, diferentemente de contextos anteriores, desencoraja processos de reação desestabilizadora, recai nas lideranças do processo de transformação o peso da responsabilidade sobre os resultados. Déficits de gestão, perda de confiança da população nas autoridades, descontentamento social, divisões na base de apoio do governo, com seu consequente enfraquecimento, poderão abrir espaço para investidas conservadoras contra a falência do Estado, da ordem e do império da lei. Como sabemos, situações dessa natureza não são incomuns na história boliviana.

\section{Luis Fernando Ayerbe}

é coordenador do Instituto de Estudos Econômicos e Internacionais da Unesp (IEEI-Unesp) e professor do Programa San Tiago Dantas de Pós-Graduação em Relações Internacionais da Unesp, Unicamp e PUC/SP. 


\section{Referências bibliográficas}

AYERBE, L. F. 2002. Estados Unidos e América Latina: a construção da hegemonia. São Paulo: Ed. Unesp.

CAMARGO, A. J. C. J. 2006. Bolívia: a criação de um novo país. Brasília: Funag. CEPAL. 1990. Balance preliminar de la economia latinoamericana. Santiago: Cepal. CHAVES ALVAREZ, M. G. 1988. "Drogas: 'o poder paralelo'”. Cadernos do Terceiro Mundo, vol. 113, pp. XXX.

CHOQUE, M. E.; MAMANI, C. R. 2003. "Reconstitución del Ayllu y derechos de los pueblos indígenas: el Movimiento Indio en los Andes de Bolivia”. In: TICONA ALEJO, E. (org.). Los Andes desde los Andes. La Paz: Ediciones Yachaywasi.

CRABTREE, J. 2006. "Desempeño económico, desigualdad y legitimidad política: Bolivia 1985-2003”. In: DOMINGO, P. (org.). Bolivia: fin de un siglo y nuevas perspectivas políticas (1993-2003). Barcelona: Ediciones Bellaterra.

DEL CAMPO, H. 1986. "Vilarroel: ejército y nacionalismo en Bolívia". In: PLÁ, A. (org.). 1986. Historia de América Latina en el siglo XX. Buenos Aires: Centro Editor de América Latina (vol. 3).

DELPIROU, A.; LABROUSSE, A. 1988. Coca coke: produtores, consumidores, traficantes e governantes. São Paulo: Brasiliense.

DO ALTO, H. 2007. “'Cuando el nacionalismo se pone el poncho': una mirada retrospectiva a la etnicidad y la clase en el movimiento popular boliviano (1952-2007)". In: SVAMPA, M.; STEFANONI, P. (orgs.). Bolivia: memoria, insurgencia y movimientos sociales. Buenos Aires: Flacso/Editorial El Colectivo.

GARCIA LINERA, A. 2006a. "Democracia liberal vs. democracia comunitaria”. In: MIGNOLO, W. (org.). 2006. Interculturalidad, descolonización del estado y del conocimiento. Buenos Aires: Ediciones del Signo.

. 2006b. "El evismo: lo nacional-popular en acción”. Observatorio Social de América Latina, n. 19, jan.-abr., pp. 25-32.

GODIO, J. 2006. El tiempo de Kirchner. Buenos Aires: Letra Griega Ediciones. HERNÁNDEZ, J.; SALCITO, A. (orgs.). 2007. La revolución boliviana: documentos fundamentales. Buenos Aires: Newen Mapu.

KESARIS, P. (org.). 1979. Intelligence and research reports, Latin America: 19411961. Washington: University Publications of America INC.

MORALES, E. 2006. "Tarea de todos, recuperar los recursos naturales". In: LEIVA, M. I. (org.). Bolivia: latinoamérica crea. Buenos Aires: Instituto Movilizador de Fondos Cooperativos C.L. 
ORELLANA AILLÓN, L. 2006. "Hacia una caracterización del gobierno de Evo Morales”. Observatorio Social de América Latina, n. 19, jan.-abr., pp. 45-54.

PLÁ, A. (org.). 1986. Historia de América Latina en el siglo XX. Buenos Aires: Centro Editor de América Latina (vol. 3).

QUIJANO, A. 2006. Estado-nación y “movimientos indígenas” en la región Andina: cuestiones abiertas. Observatorio Social de América Latina, n. 19, jan.-abr., pp. 15-24.

STEFANONI, P. 2007. "Bolivia bajo el signo del nacionalismo indígena: seis preguntas y seis respuestas sobre el gobierno de Evo Morales". In: MONASTERIOS, K.; STEFANONI, P.; DO ALTO, H. (orgs.). Reinventando la nación en Bolivia. La Paz: Clacso-Plural.

SVAMPA, M.; STEFANONI, P. 2007. "Entrevista con García Linera". In: MONASTERIOS, K.; STEFANONI, P.; DO ALTO, H. (orgs.). Reinventando la nación en Bolivia. La Paz: Clacso-Plural.

TAPIA, L. 2005. "Izquierda y movimiento social en Bolivia”. In: BARRETT, P. et al. La nueva izquierda en América Latina. Bogotá: Editorial Norma.

TRIAS, V. 1977. História del imperialismo norteamericano. Buenos Aires: Peña Lillo (vol. 2).

URQUIDI, V. 2007. Movimento cocaleiro na Bolívia. São Paulo: Hucitec.

\section{Outros materiais}

CEPAL. 2007. Anuario estadístico de América Latina y el Caribe 2006. Disponível em: <http://www.eclac.cl/publicaciones/xml/3/28063/ LCG2332B_contenido.pdf>. Acesso em: 12/03/2009.

FRIEDMAN-RUDOVSKY, J.; ROSS, B. 2008. "Exclusive: peace corps, fulbright scholar asked to 'spy' on Cubans, Venezuelans". $A B C$ News, 8 fev. Disponível em: <http:/ /www.abcnews.go.com/Blotter/ Story? $\mathrm{id}=4262036 \&$ page $=1>$. Acesso em: 12/03/2009.

GARCIA LINERA, A. 2006c. "El capitalismo andino-amazónico". Econoticias Bolivia. Disponível em: <http:/ / www.econoticiasbolivia.com/ documentos/notadeldia/debatei5.html>. Acesso em: 12/03/2009.

DIÁRIO COLATINO.COM. 2008. "Morales agradece apoyo internacional para defensa de la democracia”. 13 set. Disponível em: <http:/ /www. diariocolatino.com/es/20080913/internacionales/58795>. Acesso em: 25/06/2009.

NASH, N. C. 1993. “Conversations/Victor Hugo Cardenas; Bolivia’s vice president, first indian in high office, waits for change". Disponível em: <http://www.nytimes.com/1993/09/19/weekinreview/conversations- 
victor-hugo-cardenas-bolivia-s-vice-president-first-indian-high.html> . Acesso em: 25/06/2009.

NCPE [Nueva Constitución Política del Estado]. 2009. Disponível em: <http:/ / www.repac.org.bo/documentos/NUEVA\%20CPE.pdf >. Acesso em: 15/10/2009.

OCHOA, S. 2008. "Expulsan de Bolivia a agentes de EE.UU”. Página 12, Buenos Aires, 27 jun. Disponível em: <www.pagina12.com.ar/diario/ elmundo/4-106748-2008-06-27.html>. Acesso em: 12/03/2009.

REPAC [Representación Presidencial para la Asamblea Constituyente]. 2009. Comparación NCPE y Art. Modificados por el Congreso. Disponível em: <http://www.repac.org.bo/documentos/comparativo\%20NCPE.pdf >. Acesso em: 15/10/2009.

REUTERS. 2007. Bolivia accuses US of funding. Morales opponents. 29 ago. Disponível em: <http://www.alertnet.org/thenews/newsdesk/ N29357085.htm>. Acesso em: 25/06/2009. 
não transmitam participação aos filhos, são elas que criam condições mais ou menos favoráveis para o envolvimento dos pais em atividades participativas. No conjunto, os dados apontam associação entre a reprodução intergeracional da desigualdade social e da desigualdade política.

Palavras-chave: Participação política; socialização política; desigualdade política.

\section{DIRECT, INDIRECT AND LATE EFFECTS: PATHS OF THE INTERGENERATIONAL TRANSMISSION OF POLITICAL PARTICIPATION}

The article presents a model to explain the process through which young people become active citizens. We will see that it occurs in two complementary ways. The first is the immediate transmission, though largely driven by indirect effects, of participatory routines. The second depends on a long process, generating participation as

266 a late effect. The study shows that political participation of parents is the most effective way to "teach" children how to be participative. As regards socioeconomic background, it has an indirect effect on participation, creating a more or less favorable condition for the parents' political engagement. Overall, the data show an association between the intergenerational reproduction of social inequality and political inequality.

Keywords: Political participation; political socialization; political inequality.

\section{CRISE DE HEGEMONIA E EMERGÊNCIA DE NOVOS ATORES NA BOLÍVIA: 0 GOVERNO DE EVO MORALES}

\section{LUIS FERNANDO AYERBE}

A presidência de Evo Morales, liderança indígena e dirigente do partido Movimiento al Socialismo (MAS), abre um 
processo de transformações em diversas dimensões, em que as mudanças socioeconômicas e no poder político expressam uma perspectiva de longa duração que questiona relações de colonialidade entre uma elite dominante branca e uma maioria indígena subalterna, que se aprofundam após a independência nacional. Acompanhando essa perspectiva, predominante nos setores de apoio ao governo, a estratégia de poder do MAS não segue a tradição das revoluções sociais que operaram rupturas estruturais no modo de produção e na organização estatal bolivianas, mas aponta para uma nova revolução descolonizadora, política e cultural, que articula um indigenismo de natureza ampla, flexível e aberto aos movimentos sociais do campo popular. Essa concepção enfrenta críticas em setores da esquerda, que vislumbram uma renovação do processo de modernização capitalista iniciado em 1952, sob a liderança do Movimiento Nacionalista Revolucionario (MNR), ampliando a cidadania e democratizando o acesso ao Estado pelo reconhecimento dos indígenas como tais. Nessa perspectiva, a transformação proposta pelo MAS tenderia a favorecer uma recomposição do sistema diversificando sua base socioeconômica. A partir do contraste estabelecido por essas duas linhas de interpretação, pretendemos analisar as possibilidades estruturais da estratégia do governo de Evo Morales, tomando como referentes históricos as transformações operadas pela revolução nacionalista de 1952 e pelas reformas neoliberais iniciadas nos anos 1980.

Palavras-chave: Evo Morales; colonialidade; nacionalismo; socialismo.

\section{HEGEMONIC CRISIS AND EMERGENCE OF NEW ACTORS IN BOLIVIIA: THE GOVERNMENT OF EVO MORALES}

The presidency of Evo Morales, indigenous leader and who heads the party Movement Towards Socialism (MAS), opens a 
series of transformations in several dimensions. The changes in socio-economic and political power express the critic of longterm coloniality relations between a dominant white elite and an indigenous subordinate majority that deepens after national independence. Following this perspective, present in sectors of support to the government, the strategy of the MAS cannot follow the tradition of social revolutions that operated structural breaks in the mode of production and the state organization, but points to a new decolonizing revolution, cultural and political, articulating an indigenism of broad nature, flexible and open to popular social movements. This view is facing critics in sectors of the left that identify the renewal of capitalist modernization process initiated in 1952 under the leadership of the Nationalist Revolutionary Movement (MNR), extending citizenship and democratizing access to the state for recognition of Indians as such. From this perspective, the transformations proposed by MAS tend to favor a system restoration by diversifying its economic and social base. From the 268 contrast provided by these two lines of interpretation, we intend to analyze the structural possibilities of the strategy of the government of Evo Morales, taking as historical reference the transformations wrought by the nationalist revolution of 1952 and the neoliberal reforms initiated in 1980.

Keywords: Evo Morales; coloniality; nationalism; socialism.

\section{FREYRE, DAMATTA E O LUGAR DA NATUREZA NA "SINGULARIDADE BRASILEIRA"}

\section{SERGIO B. F. TAVOLARO}

O presente artigo investiga as maneiras pelas quais a natureza é operacionalizada em alguns empreendimentos interpretativos de Gilberto Freyre e Roberto DaMatta acerca da experiência societal brasileira. Defende-se a existência de um parentesco epistemológico entre Freyre e DaMatta que 